\title{
Highly selective hydrocarboxylation of styrene with oxalic acid or water using palladium ortho-amino arenethiolates with intramolecular coordinating nitrogen Lewis bases
}

\author{
Dennis Kruis ${ }^{a}$, Nuria Ruiz ${ }^{b}$, Maurits D. Janssen ${ }^{a}$, Jaap Boersma ${ }^{a}$, Carmen Claver ${ }^{b, *}$, \\ Gerard van Koten ${ }^{\mathrm{a}, *}$ \\ "Debye Institute, Department of Metal-Mediated Synthesis, Utrecht University, Padualaan 8, 3584 CH Utrecht, The Netherlands \\ ${ }^{\text {b }}$ Facultat de Química, Departament de Química Física i Inorgànica, Universitat Rovira i Virgili, Pl. Imperial Tarraco 1, 43005 Tarragona, Spain
}

Received 30 April 1998

\begin{abstract}
Under mild conditions and in the presence of a catalytic amount of an S,N-chelated palladium ortho-amino arenethiolate complex, styrene reacts with carbon monoxide and oxalic acid or water to selectively give 2-phenylpropanoic acid in high yield. (C) 1998 Elsevier Science S.A. All rights reserved.
\end{abstract}

Keywords: Hydrocarboxylation; Palladium complexes; Amino arenethiolate ligands; Regioselectivity

\section{Introduction}

The hydrocarboxylation and alkoxycarbonylation of olefins have been extensively studied using different palladium precursors in combination with acids and alcohols respectively $[1,2]$. In hydrocarboxylation, the selectivity of linear versus branched products is an important issue because, in general, mixtures of isomeric carboxylic acids are obtained. The reaction with palladium complexes usually requires various promoters to achieve the desired activity, selectivity and stability of the catalyst [3-5]. Palladium systems using copper chloride in acidic media have also bcen reported and the effects of additives and reaction conditions have been studied [6-8].

Styrene is one of the most studied substrates, since the commercially important 2-arylpropionic acids are representative of higher-value acids. Although research efforts have led to progress in this area [9-12], new methodologies for the catalytic hydrocarboxylation of alkenes (Eq. (1)) are of considerable interest since total control of the regioselectivity and stereoselectivity in carboxylations are still underdeveloped $[1,2]$. In the case of hydrocarboxylation of 4-methylstyrene, the regioselectivities are high when the $\mathrm{PdCl}_{2}-$ $\mathrm{CuCl}_{2}-\mathrm{PPh}_{3}$ catalyst system is used [8].

\footnotetext{
* Corresponding authors. Tel.: 349775581 37; Fax: 34977559563
}

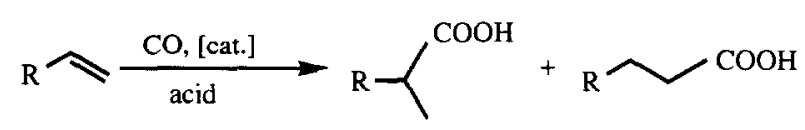

The need for milder reaction conditions in the selective hydrocarboxylation of olefins has led to palladium(II) acetate and oxalic or formic acid being used in the presence of chelating phosphorus ligands as catalysts [3-17]. The hydrocarboxylation of alkenes and alkynes reported by Alper and co-workers using these systems is a methodology of considerable interest $[15,16]$. Homogeneous catalyst precursors have been prepared using $\mathrm{Pd}(\mathrm{OAc})_{2}$ in the presence of 1,4 bis (diphenylphosphino) butane ( $\mathrm{dppb}$ ) and used as effective catalysts for hydrocarboxylation of simple and functionalised olefins [17]. These systems are particularly regioselective and, in the case of styrene, the straight chain acid is obtained achieving $86 \%$ when the ligand is dppb. The use of $\mathrm{dppb}+\mathrm{PPh}_{3}$ gives the best results, although the presence of $\mathrm{PPh}_{3}$ increases the yield but does not change the product distribution. The linear isomer is usually the dominant product.

In the last year a water-soluble catalyst system has been reported $[18,19]$. The $\mathrm{Pd}(\mathrm{OAc})_{2}-\mathrm{TPPTSH}-\mathrm{HOAc}-\mathrm{H}_{2} \mathrm{O}$ system has been used in the hydrocarboxylation of styrene in a weak acidic medium giving a branched product regioselectivity of about $90 \%$ [18]. The hydrocarboxylation of alkenes 


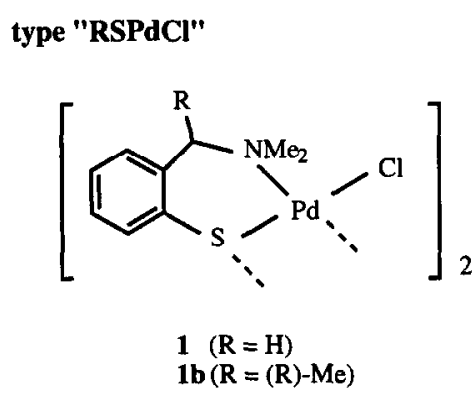

type "(RS) $)_{2} \mathbf{P d "}$<smiles>CN(C)Cc1ccccc1S[Pb]1(N(C)C)Cc2ccccc2S1</smiles>

3

$1\left[\mathrm{PdCl}\left(\mathrm{SC}_{6} \mathrm{H}_{4}\left(\mathrm{CH}_{2} \mathrm{NMe}_{2}\right)-2\right)\right]_{2}$

$1 \mathrm{~b}(\mathrm{R})-\left[\mathrm{PdCl}\left(\mathrm{SC}_{6} \mathrm{H}_{4}\left(\mathrm{C}(\mathrm{Me}) \mathrm{HNMe}_{2}\right)-2\right)\right]_{2}$

$2\left[\mathrm{PdCl}\left(\mathrm{SC}_{6} \mathrm{H}_{4} \mathrm{NMe}_{2}-2\right)\right]_{4}$

$3\left[\mathrm{Pd}\left(\mathrm{SC}_{6} \mathrm{H}_{4}\left(\mathrm{CH}_{2} \mathrm{NMe}_{2}\right)-2\right)_{2}\right]$

$4\left[\mathrm{Pd}\left(\mathrm{SC}_{6} \mathrm{H}_{4} \mathrm{NMe}_{2}-2\right)_{2}\right]$<smiles>CS(C)(C)[Pb](C)(C)Cl</smiles>

2<smiles>CN1c2ccccc2S[Pb]1(C)Sc1ccccc1</smiles>

4

Fig. 1. Catalyst precursors.

in a two-phase system using a water soluble palladium complex of trisulfonated triphenylphosphine TPPTS as catalyst and a Brönsted acid as promoter has also been reported. In that work, low $\mathrm{pH}$ values (1.8-3.0) are required to obtain high activities. The regioselectivity is $65 \%$ in linear acid [19].

The regioselectivity has been said to depend on the ligands, if esters are formed, using different phosphorus ligands $[1,2,20,21]$. The use of different mono- or diphosphine ligands has been reported for both reactions, hydrocarboxylation and alkoxycarbonylation [22]. However, the role of other ligands containing $\mathrm{N}$ or $\mathrm{S}$ donor atoms in the hydrocarboxylation reaction has been much less studied [23].

In this work we present the use of palladium aminoarenethiolates with intramolecular coordinating nitrogen Lewis bases as the catalyst precursor in the hydrocarboxylation of styrene with oxalic acid or water. The effect of varying the $P$ and $\mathrm{T}$ on the results of the catalytic reaction is also studied.

\section{Experimental}

The palladium complexes $\left[\mathrm{PdCl}\left(\mathrm{SC}_{6} \mathrm{H}_{4}\left(\mathrm{C}(\mathrm{R}) \mathrm{HNMe}_{2}\right)\right.\right.$ 2) ] 2 (1: $\mathbf{R}=\mathbf{H} ; \mathbf{1 b}$ : enantiopure, $\mathbf{R}=(\mathrm{R})-\mathrm{Me})$, [PdCl$\left.\left(\mathrm{SC}_{6} \mathrm{H}_{4} \mathrm{NMe}_{2}-2\right)\right]_{4}(2),\left[\mathrm{Pd}\left(\mathrm{SC}_{6} \mathrm{H}_{4}\left(\mathrm{CH}_{2} \mathrm{NMe}_{2}\right)-2\right)_{2}\right](3)$ and $\left[\mathrm{Pd}\left(\mathrm{SC}_{6} \mathrm{H}_{4} \mathrm{NMe}_{2}-2\right)_{2}\right]$ (4) were synthesised according to the literature $[24,25]$.

\subsection{Catalytic experiments}

A solution of styrene $(2.0 \mathrm{mmol})$, catalyst $(0.04 \mathrm{mmol}$ in palladium), $\mathrm{PPh}_{3}(0.16$ or $0.04 \mathrm{mmol}$ ) and oxalic or formic acid ( $2.5 \mathrm{mmol}$ ) in $10 \mathrm{ml}$ of dimethoxyethane was introduced into an evacuated autoclave equipped with a magnetic stirrer. Carbon monoxide was also introduced and the system was heated. When thermal equilibrium was reached, stirring was initiated. After $20 \mathrm{~h}$, the autoclave was cooled to room temperature and depressurised. Conversions and regioselectivities were determined by GC analysis of crude samples on a Hewlett-Packard model 5890 chromatograph with flame ionisation detection using a $25 \mathrm{~m}$ capillary column (Ultra 2).

\section{Results and discussion}

We recently reported a new class of $\mathrm{Pd}$ (II) complexes containing monoanionic amino arenethiolate ligands that adopt S,N-bidentate coordination at palladium [24,25] (see Fig. 1). We now report the use of palladium arenethiolate complexes of the type 'RSPdCl' ( $\left[\mathrm{PdCl}\left(\mathrm{SC}_{6} \mathrm{H}_{4}(\mathrm{C}(\mathrm{R})\right.\right.$ $\left.\left.\left.\mathrm{HNMe}_{2}\right)-2\right)\right]_{2}(1: \mathrm{R}=\mathrm{H}$; 1b: enantiopure, $\mathrm{R}=(\mathrm{R})-\mathrm{Me}$ and $\left.\left[\mathrm{PdCl}\left(\mathrm{SC}_{6} \mathrm{H}_{4} \mathrm{NMe}_{2}-2\right)\right]_{4}(2)\right)$ and '( $\left.\mathrm{RS}\right)_{2} \mathrm{Pd}$ ' ( $\left[\mathrm{Pd}\left(\mathrm{SC}_{6} \mathrm{H}_{4}\right.\right.$ $\left.\left.\left(\mathrm{CH}_{2} \mathrm{NMe}_{2}\right)-2\right)_{2}\right](3)$ and $\left.\left[\mathrm{Pd}\left(\mathrm{SC}_{6} \mathrm{H}_{4} \mathrm{NMe}_{2}-2\right)_{2}\right](4)\right)$ as catalyst precursors for the highly selective conversion of styrene to branched carboxylic acids. All hydrocarboxylation reactions were performed in 1,2-dimethoxyethane in the presence of oxalic acid with $1.6 \mathrm{~mol} \%$ of the palladium complex 
Table 1

Results of Pd arenethiolate catalysed hydrocarboxylation of styrene using oxalic acid ${ }^{\text {a }}$

\begin{tabular}{|c|c|c|c|c|c|}
\hline Entry & Precursor & $p(\operatorname{atm})$ & $T\left({ }^{\circ} \mathrm{C}\right)$ & Conversion $(\%)$ & Selectivity 2-PP (\%) \\
\hline \multicolumn{6}{|c|}{ Type 'RSPdCl' } \\
\hline 1 & 1 & 30 & 100 & 98 & 83 \\
\hline 2 & $\mathbf{l b}$ & 30 & 100 & 86 & 91 ( $4 \%$ e.e.) \\
\hline 3 & 2 & 30 & 100 & 97 & 94 \\
\hline $4^{b}$ & 2 & 30 & 100 & 60 & 100 \\
\hline 5 & 2 & 80 & 100 & 98 & 97 \\
\hline 6 & 2 & 30 & 150 & 15 & 100 \\
\hline 7 & 2 & 80 & 150 & 55 & 97 \\
\hline \multicolumn{6}{|c|}{ Type '(RS $)_{2} \mathrm{Pd}$ ' } \\
\hline 8 & 3 & 30 & 100 & 35 & 100 \\
\hline 9 & 3 & 80 & 100 & 45 & 100 \\
\hline 10 & 4 & 30 & 100 & 87 & 100 \\
\hline 11 & 4 & 80 & 100 & 97 & 98 \\
\hline 12 & $\mathrm{PdCl}_{2}(\mathrm{PhCN})_{2}$ & 30 & 100 & 100 & 89 \\
\hline
\end{tabular}

${ }^{a}$ Reaction conditions: $2.5 \mathrm{mmol}$ styrene, $10 \mathrm{ml}$ DME (1,2-dimethoxyethane), 0.04 mmol precursor, 2.5 mmol $\mathrm{H}_{2} \mathrm{C}_{2} \mathrm{O}_{4} \cdot 2 \mathrm{H}_{2} \mathrm{O}, \mathrm{P}: \mathrm{Pd}=4: 1$, reaction time: $20 \mathrm{~h}$. ${ }^{b} \mathrm{P}: \mathrm{Pd}=1: 1$.

and $\mathrm{PPh}_{3}$ as the additive. The presence of $\mathrm{PPh}_{3}$ was found to be essential for catalysis. In the absence of this additive, no conversion was detectable when oxalic acid was used and less than $5 \%$ was noted in runs with formic acid.

At a temperature of $100^{\circ} \mathrm{C}$ and a CO pressure of $30 \mathrm{~atm}$ (non-S.I. unit: $1 \mathrm{~atm}=101325 \mathrm{Nm}^{-2}$ ) these catalysts provide conversions of $34-98 \%$ and regioselectivities of $83-$ $100 \%$ for 2-phenylpropanoic acid (2-PP) (Table 1). Under these conditions complexes 1 and 2 give over $97 \%$ conversion (entries 1 and 3) with complex 2 providing the best regioselectivity for 2-PP (94\%, entry 3 ). Lowering the P:Pd ratio from 4:1 to 1:1 causes a drop in conversion, although regioselectivity increases (entry 4 ). When the $\mathrm{CO}$ pressure is increased to $80 \mathrm{~atm}$, the conversion is maintained but the regioselectivity is slightly increased (entry 5 ). With a reaction temperature of $150^{\circ} \mathrm{C}$ for precursor 2 (entries 6 and 7), conversions are lower but regioselectivities are higher with the concomitant formation of palladium black at the end of the reaction.

In general, higher temperatures lead to decomposition of the palladium arenethiolate catalyst and lower the conversion dramatically, although the regioselectivity improves. Higher pressures, however, increase conversion and have little overall effect on the selectivity.

Conversions using mononuclear complexes 3 and 4 were lower than conversions using complexes 1 and 2, but the regioselectivity increased to $100 \%$ (entries 8 and 10 ). Increasing the $\mathrm{CO}$ pressure to $80 \mathrm{~atm}$ also led to an increase in conversion (entries 9 and 11).

In an attempt to obtain chiral induction in the branched isomers, the chiral catalyst precursor $1 \mathbf{b}$ was also tested. Conversion and selectivity were as expected, but enantiomeric excesses did not exceed $4 \%$ (entry 2 ). This may mean that the chiral information is not present in the actual catalytically active species, i.e., the thiolate ligand is cleaved from the palladium centre. If this is so, then it should be possible to use catalyst precursors that do not have a thiolate moiety. Indeed, when we tested $\mathrm{PdCl}_{2}(\mathrm{PhCN})_{2}$ as a catalyst precursor, conversion into acids was complete, although the regioselectivity towards the branched acid was lower ( $89 \%$, entry 12).

The different regioselectivities of the two systems should be noted because it shows that the amino arenethiolate ligand has a considerable effect on the catalytic cycle.

As has been mentioned in Section 1, most of the studies on the hydrocarboxylation reaction are made in the presence of acidic media. To further our knowledge of these precursors, we carried out the reaction using water in place of acidic media as previously studied for other palladium systems [3]. When catalytic precursors 2 and 4, as well as $\mathrm{PdCl}_{2}(\mathrm{PhCN})_{2}$, were tested in the hydrocarboxylation of styrene using water instead of oxalic acid, we did observe conversion into acids (Table 2). Using 2, conversion was low when 2 equiv. of water (with respect to styrene) were used, but when the excess of water was increased ( 20 equiv.) conversion was almost complete and selectivity to 2-PP was high. At low water concentrations, 4 also gave low conversions (entry 3 ).

Table 2

Results of Pd arenethiolate catalysed hydrocarboxylation of styrene using water $^{\text {a }}$

\begin{tabular}{llclc}
\hline Entry & Precursor & $\begin{array}{l}\text { Water } \\
(\mathrm{mmol})\end{array}$ & $\begin{array}{l}\text { Conversion } \\
(\%)\end{array}$ & $\begin{array}{l}\text { Selectivity 2-PP } \\
(\%)\end{array}$ \\
\hline 1 & 2 & 5 & 22 & 100 \\
2 & 2 & 50 & 97 & 90 \\
3 & 4 & 5 & 13 & 100 \\
4 & $\mathrm{PdCl}_{2}\left(\mathrm{PhCN}_{2}\right.$ & 50 & 99 & 87
\end{tabular}

a Reaction conditions: $2.5 \mathrm{mmol}$ styrene, $10 \mathrm{ml} \mathrm{DME,} 0.04 \mathrm{mmol}$ precursor, $30 \mathrm{~atm} \mathrm{CO}, 100^{\circ} \mathrm{C}, \mathrm{P}: \mathrm{Pd}=4: 1$, reaction time: $20 \mathrm{~h}$. 
Like the experiments using oxalic acid shown in Table 1, the regioselectivity obtained with aminothiolate systems is higher than in the case of the $\mathrm{PdCl}_{2}(\mathrm{PhCN})_{2}$ precursor.

The regioselectivity observed in these systems is quite unlike the regioselectivities previously reported for $\mathrm{Pd} /$ $\mathrm{dppb} /$ formic or oxalic acid ( $\mathrm{dppb}=1,4$-bis (diphenylphosphino) butane) catalytic systems $[13,14,17]$ in which a cationic $\mathrm{Pd}(\mathrm{II})$ complex $[\mathrm{PdH}(\mathrm{CO})(\mathrm{dppb})]^{+}\left[\mathrm{HOC}(\mathrm{O}) \mathrm{CO}_{2}\right]^{-}$ is proposed as an important intermediate [17].

We are at present carrying out further studies on the intermediate compounds in our system to shed some light on the nature of this unusual selectivity. We are also studying the role of the ancillary ligands $\mathrm{NS}^{-}$in 1-4 and $\mathrm{PhCN}$ in $\mathrm{PdCl}_{2}(\mathrm{PhCN})_{2}$.

\section{Conclusions}

In conclusion, although triphenylphosphine is required as auxiliary ligand, these catalyst precursors lead to the total regioselective formation of branched carboxylic acids, which is not frequently observed in the hydrocarboxylation reaction. Furthermore, neither co-catalysts nor acidic media are required.

\section{Acknowledgements}

This study is part of the COST Chemistry D2 project (Selective Synthesis) entitled 'Stereoselective reactions promoted by metal complexes with chiral ligands containing sulfur donors' and financial support is gratefully acknowledged. Dr R.A. Gossage is gratefully acknowledged for his careful checking of the manuscript.

\section{References}

[1] M. Beller, B. Cornils, C.D. Frohning, C.W. Kohlpaintner, J. Mol. Catal. A 104 (1995) 17.

[2] B. Cornils, W.A. Herrmann (Eds.), Applied Homogeneous Catalysis with Organometallic Compounds, VCH, Germany, 1996.

[3] D.M. Fenton, J. Org. Chem. 38 (1973) 3192.

[4] G. Cavinato, L. Toniolo, C. Botteghi, J. Mol. Catal. 32 (1985) 211.

[5] G. Cavinato, L. Toniolo, J. Organomet. Chem. 187 (1990) 195.

[6] H. Alper, N. Hamel, J. Am. Chem. Soc. 112 (1990) 2803.

[7] H. Alper, N. Hamel, J. Chem. Soc., Chem Commun., (1990) 1356.

[8] J.-Y. Yoon, E.J. Jang, K.H. Lee, J.S. Lee, J. Mol. Catal. 118 (1997) 181 and Refs. therein.

[9] A.N. Ajjou, H. Alper, Macromolecules 29 (1996) 1784.

[10] J.M. Baird, J.R. Kern, G.R. Lee, D.J. Morgans, M.L. Sparacino, J. Org. Chem. 56 (1991) 1928.

[11] H. Alper, J.B. Woell, B. Despeyroux, D.J.H. Smith, J. Chem. Soc., Chem. Commun., (1983) 1270.

[12] J.-J. Brunet, D. Neibecker, R.S. Srivastava, Tetrahedron Lett. 34 (1993) 2759.

[13] B. Ali, H. Alper, J. Mol. Catal. 77 (1992) 7.

[14] B. Ali, H. Alper, J. Org. Chem. 58 (1993) 3595.

[15] B. El Ali, G. Vasapollo, H. Alper, J. Org. Chem. 58 (1993) 4739.

[16] D. Zargarian, H. Alper, Organometallics 12 (1993) 712.

[17] B. Ali, H. Alper, J. Mol. Catal. 80 (1993) 377.

[18] B. Xie, Y. Kou, Y. Ying, J. Mol. Catal. 11 (1997) 81.

[19] S. Tilloy, E. Monflier, F. Bertoux, Y. Castanet, A. Mortreux, New J. Chem. 21 (1997) 529.

[20] G. Consiglio, S.A. Nefkens, C. Pisano, F. Wenzinger, Helv. Chim. Acta 74 (1991) 323.

[21] G. Consiglio, M. Marchetti, Chimia 30 (1976) 1.

[22] H. Zhou, J. Hou, J. Cheng, S. Lun, H. Fu, H. Wang, J. Organomet. Chem. 543 (1997) 227.

[23] M.I. Terekhova, T.E. Kron, N.A. Bondarenko, É.S. Petrov, E.N. Tsvetkov, Izv. Akad. Nauk, Ser. Khim. 9 (1996) 1784.

[24] Complexes 2 and 4: M.D. Janssen, D.M. Grove, G. van Koten, A.L. Spek, Recl. Trav. Chim. Pays-Bas 115 (1996) 286.

[25] Complexes 1, 1b and 3: D. Kruis, J. Boersma, A.L. Spek, G. van Koten, unpublished results. 